\title{
Use and completion of partograph during labour is associated with a reduced incidence of birth asphyxia: a retrospective study at a peri-urban setting in Ghana
}

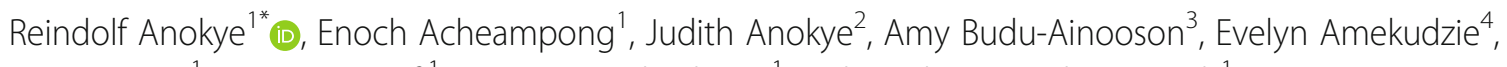
Isaac Owusu', Naomi Gyamfi ${ }^{1}$, Agyei Gyimah Akwasi ${ }^{1}$ and Wisdom Kwadwo Mprah ${ }^{1}$

\begin{abstract}
Background: Morbidity of birth asphyxia has been estimated to be 42 million disability-adjusted life years. The study sought to assess the impact of the use and completion of partograph during labour on reducing birth asphyxia at the St Anthony's Hospital, Dzodze, in the Volta Region of Ghana.

Methods: A retrospective study design using a quantitative approach was adopted for the study. A simple random sampling technique was used to select a total of 200 folders of labouring women who were admitted and delivered at St Anthony's Hospital, Dzodze, between 1st May 2015 and 30th April 2016. A structured checklist, which was developed by using labour and foetal monitoring parameters based on the standards of the World Health Organization partograph usage, was used to review all the 200 existing maternal records.

Results: The findings revealed that partographs were used by midwives at St Anthony's Hospital with the majority of the maternal folders fully completed. The use and completion of partograph were found to be associated with less non-asphyxiated birth outcomes. Labours which were monitored with partograph were 4.29 times less likely to result in birth asphyxia [AOR (95\% Cl) $4.29(1.35-14.81)$ ], and those that were monitored with a completed partograph were 5.3 times less likely to result in birth asphyxia [AOR (95\% Cl) 5.31 (2.011-16.04)].

Conclusion: Midwives used partographs during labour at St Anthony's Hospital. The use and completion of partograph were significantly associated with a reduced incidence of birth asphyxia at the hospital. Birth asphyxia could be reduced if partographs are used and completed by midwives during labour in all cases.
\end{abstract}

Keywords: Disability prevention, Labour, Partograph, Asphyxia, Ghana

\section{Introduction}

Obstructed labour is a significant cause of not only maternal death but also short- and long-term disability [1]. In developing countries, obstructed labour remains one of the primary causes of birth asphyxia [2].

Nearly 1 in every 1000 live births in developed countries, as compared to 5 to 10 in every 1000 live births in developing countries, suffer severe perinatal asphyxia causing death

\footnotetext{
* Correspondence: reindolfanokye@yahoo.com

${ }^{1}$ Centre for Disability and Rehabilitation Studies, Department of Community Health, Kwame Nkrumah University of Science and Technology, Kumasi, Ghana

Full list of author information is available at the end of the article
}

or severe neurological impairment [3]. Lawn et al. [4] highlighted that the disability-adjusted life years (DALYs) denoting the number of years lost due to ill-health, disability, or early death attributed to the burden of morbidity of birth asphyxia is estimated to be 42 million.

The effects of asphyxia in the short term could be multi-organ dysfunction or even death [5] and could result in the development of cerebral palsy; developmental delay; visual, hearing, and intellectual impairment; epilepsy; and learning and behavioural problems in the long term $[5,6]$. Birth asphyxia is also concomitant with a wide range of neurodevelopmental and neurological disorders and disability in life [7]. Lawn et al. [4] added

(C) The Author(s). 2019 Open Access This article is distributed under the terms of the Creative Commons Attribution 4.0 International License (http://creativecommons.org/licenses/by/4.0/), which permits unrestricted use, distribution, and 
that the severe occurrence of birth asphyxia is associated with disorders that extremely blight an individual's integration into society as an independent adult. Furthermore, it is becoming increasingly apparent that more subtle cognitive and affective deficiencies are primary and permanent consequences of birth asphyxia and are in most need of prevention [8]. According to Gorgos [9], the accompanying effects of birth asphyxia have a resilient and ubiquitous harmful effect on both the quality of life of the child and the caregivers of which include anxiety, depression, and coping problems.

Teenagers with a diagnosis of asphyxia at birth are much more likely to perform poorly in tests of intellectual development and to suffer epilepsy compared to peers with no asphyxia [10]. Cognitive dysfunction may also manifest as problematic school performance, social maladjustment, and behavioural difficulties in adults who had asphyxia at birth [11]. Verbal processing and memory can be negatively affected [12], and vision and hearing can be impaired [13]. Attention deficit hyperactivity disorder, schizophrenia, and autism are neuropsychiatric disorders dominant in survivors of birth asphyxia [14].

To reduce these obstetric complications, the World Health Organization recommends the use of partograph especially in low resourced countries [15]. Partograph is a tool that serves as a first warning system which assists in early decision making on transfer action and ongoing evaluation of the effect of midwifery interventions [16]. It is an inexpensive pictorial, graphical representation of maternal and foetal observations recorded during the active stage of labour [17]. The use of the partograph is recommended for routine monitoring of labour and helps the health care provider in identifying slow progress in labour and aid in timely and appropriate interventions to prevent prolonged labour and obstructed labour [18]. This study sought to evaluate the use and documentation of partograph in labour and the incidence of birth asphyxia at the St Anthony's Hospital, Dzodze, in the Volta Region of Ghana.

\section{Methods}

\section{Study site}

The study was conducted at the maternity unit of the St Anthony's Hospital, Dzodze, in the Ketu North district of the Volta Region of Ghana. It is a Catholic Church-owned facility under the Keta-Akatsi Diocese of Ghana. It is a district hospital with a catchment population of about 260,000 people. Referrals are received from Ketu South, Akatsi, Keta, and Ho district. About 25 to $30 \%$ of the patients seen in this facility come from the neighbouring Republic of Togo. A total staff strength of 173 includes 20 midwives. The bed capacity of the hospital is 236; out of this, 30 beds serve the maternity unit which consists of antenatal area, delivery area, and lying-in area and the average total number of delivery per month is 120 . The hospital was selected because it serves a large catchment population of about 260,000 people. Moreover, it receives referrals from Ketu South, Akatsi, Keta, and Ho district.

\section{Study design}

For this study, a retrospective design was adopted using a quantitative approach. A retrospective study uses existing data that have been recorded for reasons other than research [19]. In healthcare, these are often called "chart reviews" because the data source is the medical record [19].

\section{Sample and sampling}

Folders of all women in labour who were admitted and delivered at St Anthony's Hospital, Dzodze, between 1 May 2015 and 30 April 2016 were the population used for the study. The 2015/2016 year was randomly selected out of other year groups that were eligible for selection.

The eligibility criteria for selection were folders of labouring women who were admitted and delivered at the facility's maternity unit between the selected period indicated. Therefore, all folders that were not recorded within this period were excluded from the study. Out of 398 folders, 200 folders of labouring women who were admitted and delivered at the facility's maternity unit between this period were used as the sample size for the study.

The sample size was calculated using the Yamane formula [20] where 95\% confidence level and 0.05 precision levels were used. The calculation of the sample size was based on the Yamane simplified formula for proportions equation:

$$
n=\frac{N}{1+N(\boldsymbol{e})^{2}}
$$

Therefore, $n$ is the sample size, $N$ is the population size, and $e$ is the level of precision. Overall, 398 folders of labouring women, who were admitted and delivered at the facility's maternity unit between the period of 1 May 2015 and 30 April 2016, were found. The formula was applied to select the study sample.

A simple random sample was used. In this case, a sample frame was drawn using all the folder numbers of the labouring women who were admitted and delivered within the facility between the period that was considered for the study. The folder numbers were randomly picked until the 200th folder was selected.

\section{Instrumentation}

A structured checklist, which was developed by using labour and foetal monitoring parameters based on the standards of the World Health Organization 
partograph usage, was used to review all the 200 existing maternal records.

\section{Data analysis}

At the end of the entire data collection process, the data was entered into Statistical Package for Social Sciences (SPSS) version 21.0 and analysed using logistic regression with odds ratio used to present strength of association between risk factors and outcomes. The analysed data was organised into frequency tables and represented on pie charts and tables. The study utilised both descriptive and inferential statistical techniques in data analysis.

\section{Ethics approval}

Ethical clearance was obtained from the committee on Human Research Publications and Ethics (CHRPE) of the Kwame Nkrumah University of Science and Technology.

An introductory letter from the Department of Midwifery of the Kwame Nkrumah University of Science and Technology was obtained to embark on the study. Permission was obtained from the administrator of St Anthony's Hospital to carry out the study. All information from the client's folder was treated confidentially. The identity of the study respondents was kept confidential throughout the study. In order to maintain anonymity, participants' identity was not disclosed for this study. The administrators of the hospital approved the use of the facility for the study, and ethical approval was obtained from them.

\section{Results}

\section{Demographic data}

Table 1 shows an analysis of the distribution of the mother's demographic data. The results indicate that more than half of the mothers were between 24 and $29(29 \%)$ years as well as between 30 and 35 years (30\%).

The table also shows that the majority (67\%) were married while a few (2\%) had divorced or were separated.

\section{Use and documentation of partograph}

From Table 2, out of the 200 client's folders reviewed, 174 representing $87 \%$ had partographs in their folders while 26 folders representing 13\% had no partographs in them.

Out of 174 maternal folders that had partograph, 139 representing $80 \%$ were fully completed while 35 representing $20 \%$ were not fully completed.
Table 1 Distribution of patients demographic data

\begin{tabular}{|c|c|c|c|}
\hline Variables & Characteristics & Frequency & Percentage \\
\hline \multicolumn{4}{|c|}{ Age } \\
\hline & $18-23$ years & 50 & 25 \\
\hline & 24-29 years & 58 & 29 \\
\hline & 30-35 years & 60 & 30 \\
\hline & $36-41$ years & 28 & 14 \\
\hline & Above 41 & 4 & 2 \\
\hline \multicolumn{4}{|c|}{ Marital status } \\
\hline & Single & 62 & 31 \\
\hline & Married & 134 & 67 \\
\hline & Divorced/separated & 4 & 2 \\
\hline \multicolumn{4}{|l|}{ Parity } \\
\hline & 0 & 76 & 38 \\
\hline & 1 & 86 & 43 \\
\hline & 2 & 14 & 7 \\
\hline & 3 & 24 & 12 \\
\hline & 4 and above & 0 & 0 \\
\hline
\end{tabular}

Table 2 further shows that all the 174 folders in which partograph were used had cervical dilatation plotted to standard.

Also, 158 partographs representing 91\% had foetal head descent recorded to standard while 16 partographs representing $9 \%$ had the descent of the foetal head not recorded at all.

Furthermore, 167 partographs representing 96\% had foetal heart rate (FHR) recorded to standard while 7 of the partographs representing $4 \%$ had FHR not recorded at all.

From Table 2, 161 partographs representing 93\% had amniotic fluid recorded to standard while 13 partographs representing 7\% had amniotic fluid not indicated at all. Also, 162 partographs representing 93\% had foetal head moulding recorded to standard while 20 partographs representing $7 \%$ had foetal head moulding not recorded at all. Table 2 further shows that 166 partographs representing 95\% had uterine contraction recorded to standard while eight partographs representing $5 \%$ had no uterine contraction recorded at all.

Moreover, 149 partographs representing 86\% progressed well without crossing the action line while 25 partographs representing $14.4 \%$ crossed the action line.

On the mode of delivery, 174 patients representing $87 \%$ had spontaneous vaginal delivery (SVD) while 26 patients representing $13 \%$ delivered by Caesarean section (CS). 
Table 2 Use and documentation of partograph

\begin{tabular}{|c|c|c|c|}
\hline Variables & Characteristics & Number & Percentage \\
\hline \multicolumn{4}{|c|}{ Partograph use } \\
\hline & Yes & 174 & 87 \\
\hline & No & 26 & 13 \\
\hline \multicolumn{4}{|c|}{ Partograph completion } \\
\hline & Yes & 139 & 80 \\
\hline & No & 35 & 20 \\
\hline \multicolumn{4}{|c|}{ Cervical dilatation documentation } \\
\hline & Yes & 174 & 100 \\
\hline & No & 0 & 0 \\
\hline \multicolumn{4}{|c|}{ Documentation of descent } \\
\hline & Yes & 158 & 91 \\
\hline & No & 16 & 9 \\
\hline \multicolumn{4}{|c|}{ Documentation of FHR } \\
\hline & Yes & 167 & 96 \\
\hline & No & 7 & 4 \\
\hline \multicolumn{4}{|l|}{$\begin{array}{l}\text { Documentation of } \\
\text { amniotic fluid }\end{array}$} \\
\hline & Yes & 161 & 93 \\
\hline & No & 13 & 7 \\
\hline \multicolumn{4}{|c|}{ Documentation of foetal head moulding } \\
\hline & Yes & 162 & 93 \\
\hline & No & 12 & 7 \\
\hline \multicolumn{4}{|c|}{ Documentation of uterine contraction } \\
\hline & Yes & 166 & 95 \\
\hline & No & 8 & 5 \\
\hline \multicolumn{4}{|c|}{ Crossing of the action line } \\
\hline & Yes & 149 & 86 \\
\hline & No & 25 & 14 \\
\hline \multirow[t]{2}{*}{ Mode of delivery } & SVD & 174 & 87 \\
\hline & CS & 26 & 13 \\
\hline
\end{tabular}

Foetal outcome concerning the use and completeness of partograph

Figure 1 shows that 188 babies representing 94\% were born alive while 12 babies representing 6\% were stillborn.

\section{Condition of a newborn baby}

Figure 2 shows that out of the 188 live births, 147 babies representing $73 \%$ were born with no asphyxia while 41 live births representing $21 \%$ were born with different degrees of asphyxia.

\section{First minute Apgar score}

From Fig. 3, babies born with Apgar score of zero at the 1 st minute were 12 representing 6\%, Apgar score (AS) from 2 to 3 were 27 representing 13\%, AS from 4 to 6

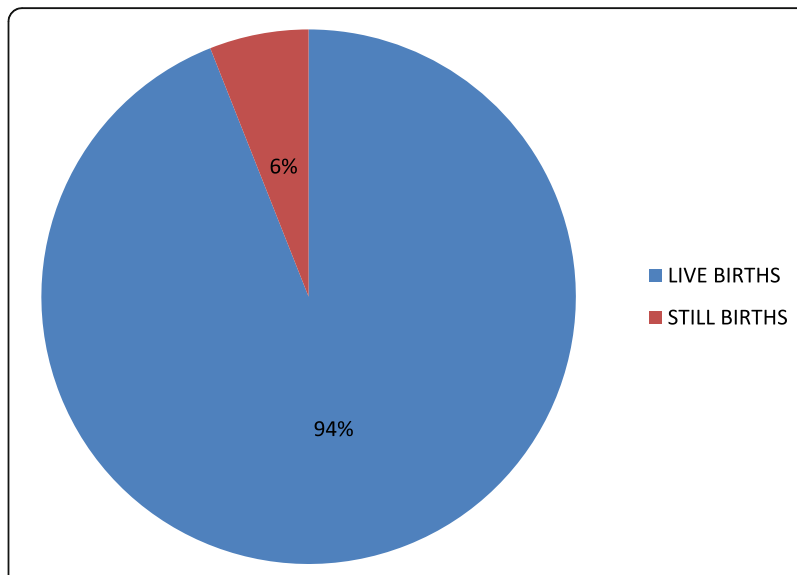

Fig. 1 Foetal outcome

were 60 representing 30\%, and AS 7 and above were 101 representing $51 \%$.

\section{Fifth minute Apgar score}

From Fig. 4, babies with Apgar score of zero at the 5th minute were still at 12 representing 6\%, Apgar score from 1 to 3 at 5 th minute were 8 representing $4 \%$, Apgar score from 4 to 6 were 32 representing $16 \%$, and Apgar scores from 7 and above were 148 representing $74 \%$.

\section{Foetal outcome and the use of partograph}

Table 3 displays a summary of the results of the univariate and multivariate analysis. In both the univariate analysis and the multivariate analysis, the use and documentation completion of partograph had a significant association with a birth outcome such as birth asphyxia $(p=0.002)$ and $(p=0.001)$.

Multivariate logistic regression analysis indicates that labours which were monitored with partograph were 4.29 times less likely to result in birth asphyxia [AOR

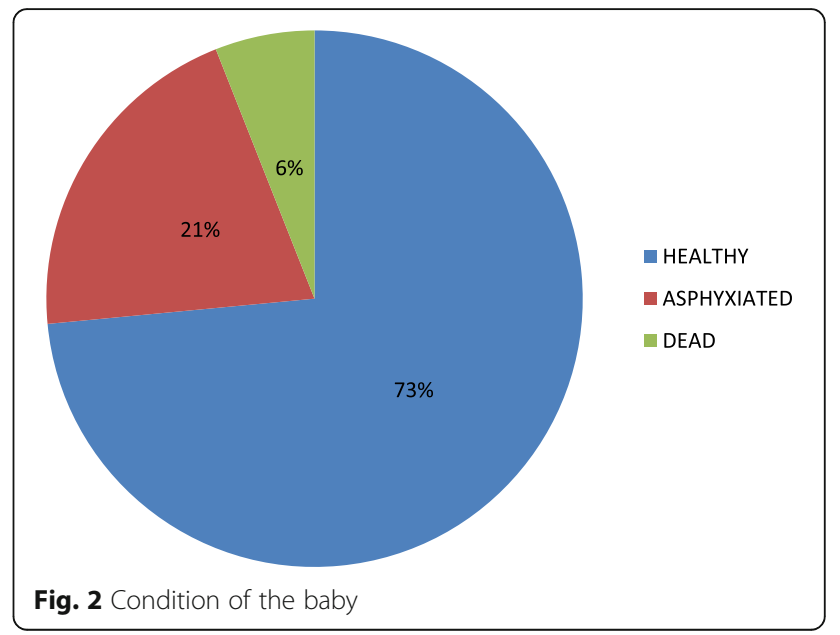




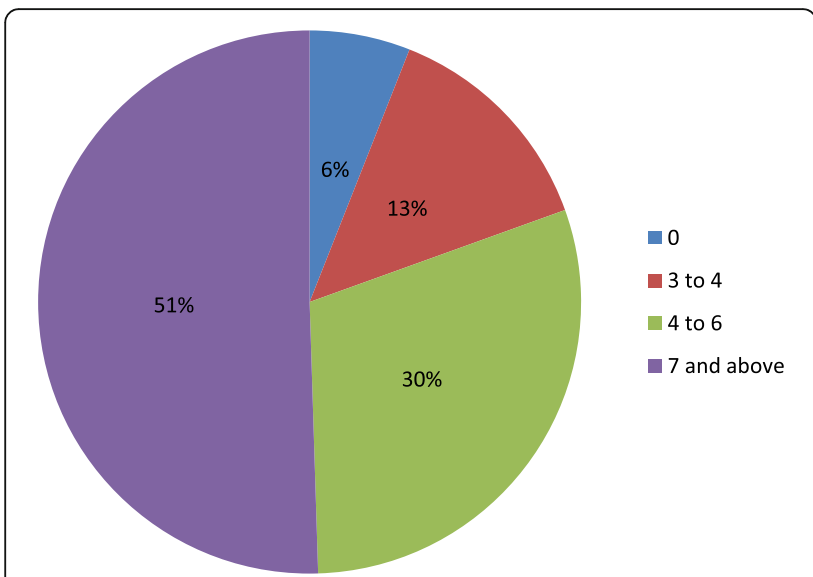

Fig. 3 First minute Apgar score

(95\% CI) 4.29 (1.35-14.81)], and those that were monitored with a completed partograph were 5.3 times less likely to result in birth asphyxia [AOR (95\% CI) 5.31 (2.011-16.04)]

\section{Discussion}

Midwives in Ghana received specific training in the use of partograph in 2010 [21]. Knowledge in the use of partograph promotes confidence, reduces the length of labour, and reduces Caesarean section rate and intrapartum stillbirths, but the commitments to its use in providing the desired effects are worrying. Irrespective of how knowledgeable obstetric caregivers are regarding the partograph, its use and documentation of the labour monitoring parameters during labour is often a challenge. The findings revealed that $87 \%$ of the folders had indications of partograph use while $13 \%$ had no such information on partographs use. This is worrying as partograph use is required in every delivery. A lower proportion of partograph usage was reported by Opoku

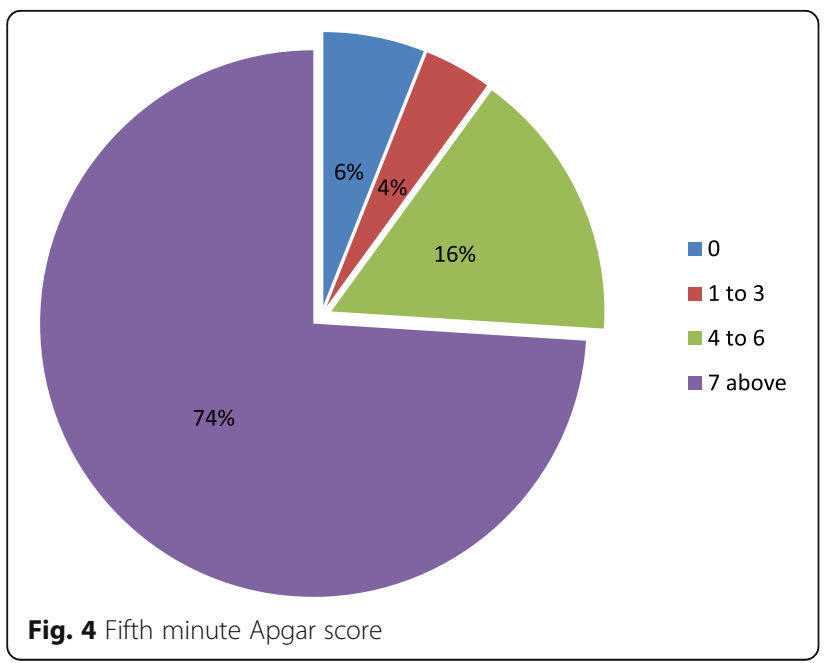

and Nguah [22] in a study in Ghana where out of 809 deliveries, partograph was used in $54.6 \%$ of the deliveries. A slightly higher proportion of usage was reported in a Ugandan study reporting a $69.9 \%$ partograph usage during deliveries [23]. However, a deficient proportion of partograph usage was reported in an Ethiopian study, where only $12 \%$ of the cases were monitored on a partograph [24].

Contrary to study reports [25] suggesting incomplete documentation of parameters on the partograph by midwives, this study, however, found $80 \%$ of the partographs properly filled on all parameters. A study in Tanzania found that only $8.9 \%$ of partographs had all parameters completed to standard [26]. A Malawian study also reported that only $10 \%$ of folders had partographs filled wholly and correctly [27]. The findings of Opiah et al. [28] suggesting that there is reduced utilisation of the partograph by midwives despite increased knowledge is also in contrast to the findings of this study. The $80 \%$ recorded in this study is encouraging and should be commended. Similarly, a study in Ethiopia found that $80 \%$ of partographs had key events correctly filled and completed [29]. Nonetheless, the $20 \%$ of the partograph that were not wholly filled should be a cause for concern as incomplete documentation of all parameters on the partograph has been associated with late referrals, missing of problems, and perinatal deaths [23, 30, 31]. This suggests the need for ongoing in-service training of midwives on proper usage of the partograph. Proper supervision, monitoring, and supportive follow-ups on midwives together with in-service training will go a long way to improve outcomes for both mothers and foetuses. This has been proven in studies by Fahdhy and Chongsuvivatwong [32] in Indonesia and Ogwang et.al. [23] in Uganda.

The partographs reviewed in this study showed shreds of evidence of documentation of FHR and foetal descent. Ninety-six per cent $(96 \%)$ and $91 \%$ of the partographs had documentation on FHR and foetal descent respectively. However, the parameters that were monitored were not adequately documented. A similar problem was reported in a study in Malawi by Thorsen and Sundby [33]. Monitoring of FHR is strongly associated with outcomes for the foetuses while FHR and descent have been associated with the choice or method of delivery [33]. Other studies have shown that improper monitoring of the FHR may lead to foetal asphyxia and poor Apgar scores [30, 31, 34].

This partly may explain the $21 \%$ asphyxiated babies and the $12(6 \%)$ new stillbirths that were recorded in this study. A controlled study reported that before the introduction of partograph, 48 (9.6\%) babies needed resuscitation, but this dropped to 21 (4.2\%) in those deliveries with proper partographic monitoring. Two (2) fresh stillbirths 
Table 3 Association between use and documentation completion of partograph and incidence of asphyxia

\begin{tabular}{|c|c|c|c|c|c|c|}
\hline \multirow[t]{2}{*}{ Variables } & \multicolumn{2}{|l|}{ Asphyxia } & \multicolumn{2}{|l|}{ Univariate } & \multicolumn{2}{|l|}{ Multivariate $^{a}$} \\
\hline & Present $(n)$ & Absent $(n)$ & $\mathrm{OR}(95 \% \mathrm{Cl})$ & $P$ value & $\mathrm{OR}(95 \% \mathrm{Cl})$ & $P$ value \\
\hline \multicolumn{7}{|l|}{ Age } \\
\hline $18-23$ years & 10 & 40 & 1.00 & & 1.00 & \\
\hline 24-29 years & 18 & 30 & 2.72 & 1.317 & $2.91(0.14-6.01)$ & 0.312 \\
\hline $30-35$ years & 9 & 51 & $1.91(0.12-18.90)$ & 1.061 & $1.94(0.98-8.09)$ & 0.197 \\
\hline $36-41$ years & 3 & 25 & $16.5(3.54-45.49)$ & 0.081 & $5.14(1.01-21.8)$ & 0.091 \\
\hline Above 41 & 1 & 3 & $5.12(0.02-5.21)$ & 1.020 & $0.62(0.02-6.00)$ & 0.101 \\
\hline \multicolumn{7}{|l|}{ Parity } \\
\hline 0 & 12 & 64 & 1.00 & & 1.00 & \\
\hline 1 & 14 & 72 & $1.02(0.44-2.35)$ & 0.838 & $1.62(0.41-4.60)$ & 0.425 \\
\hline 2 & 10 & 4 & $1.14(0.32-4.01)$ & 0.912 & $2.00(0.17-21.05)$ & 0.291 \\
\hline 3 & 5 & 19 & $1.39(0.81-1.91)$ & 1.109 & $1.09(0.14-1.78)$ & 0.431 \\
\hline 4 and above & 0 & 0 & $1.10(0.48-2.48)$ & 1.091 & $0.81(0.14-3.39)$ & 1.00 \\
\hline \multicolumn{7}{|l|}{ Partograph use } \\
\hline Yes & 23 & 151 & $5.89(2.41-23.02)$ & 0.002 & $4.29(1.35-14.81)$ & 0.033 \\
\hline No & 18 & 8 & 1.00 & & 1.00 & \\
\hline \multicolumn{7}{|c|}{ Partograph completion } \\
\hline Yes & 9 & 130 & $7.28(4.08-21.17)$ & $<0.001$ & $5.31(2.011-16.04)$ & 0.021 \\
\hline No & 32 & 3 & 1.00 & & 1.00 & \\
\hline
\end{tabular}

$O R$ odds ratio, $\mathrm{Cl}$ confidence interval

${ }^{a}$ Mutually adjusted

and seven (7) neonatal deaths were recorded before the introduction of the partograph, but only 2 fresh stillbirths were recorded during the use of partograph and it clearly shows a decrease in perinatal mortality from 3.6 to $0.8 \%$; this shows a significant impact of partograph on neonatal outcomes [35]. The findings of Javed et al. [36] confirm earlier assertions by Bosse et al. [30], Nyamtema et al. [31], and WHO [34]. Monitoring of descent as emphasised earlier has been reported to be strongly associated with the method of delivery. Appropriate decisions on the right method of delivery can be made thereby avoiding maternal and foetal complications [37]. In this study, $87 \%$ had spontaneous vaginal delivery (SVD) while 26 patients representing 13\% delivered by Caesarean section (CS).

The overall birth outcomes for the foetuses especially were good. This is in contrast to the poor outcomes reported in Malawi by Kitila et al. [27] but consistent with outcomes reported by Javed et al. [36].

Other parameters that were documented on the partograph were foetal head moulding and uterine contraction. Ninety-three per cent $(93 \%)$ of the partograph had foetal head moulding recorded on them. On the contrary, a study by Bogale and Markos [38] reported that out of the $239(69.9 \%)$ partographs, only $3(1.3 \%)$ of moulding of the foetal head were recorded. Documentation on uterine contraction was $95 \%$. This is somewhat in contrast to the lower percentage of documentation on uterine contractions recorded in a study conducted by Bogale and Markos [38]. The considerable difference in the findings may be attributed to the difference in the sample sizes and the level of utilisation of the partograph based on hospital policies/protocols. A study conducted in eight hospitals in Ecuador reported a massive difference in the utilisation of the partograph among countries and health facilities [39].

This study showed that labours monitored with the partograph were 4.29 times less likely to result in birth asphyxia. This is consistent with that observed in Nigeria, Malawi, Pakistan, and India [40, 27, 36, 41].

\section{Limitations}

The study focused on assessing the association between partograph use and documentation and asphyxia overlooking other maternal and health care system risk factors. Also, 200 folders were assessed, and a more significant number could have been selected if other healthcare facilities were used. However, the findings of the study do not fall short in any way, and the aim of the study was achieved.

\section{Conclusion}

This study confirmed the use of partographs during labour and the relationship that exist between the use of partographs and birth outcomes. It can, therefore, be concluded that the use and completion of partograph 
were significantly associated with a reduced incidence of birth asphyxia at St Anthony's Hospital, Dzodze, in the Ketu North district of the Volta Region of Ghana.

\section{Recommendation}

Hospital authorities and the Ministry of Health should ensure that midwives use partographs at the Hospital during labour.

Hospital authorities should ensure that all active labour cases are monitored on a partograph.

Furthermore, a monthly review of clients who delivered at the facility should be regularly done by midwives and hospital authorities.

\section{Abbreviations}

FHR: Foetal heart rate; SPSS: Statistical Package for Social Sciences

\section{Acknowledgements}

Our gratitude goes out to the management and staff of St Anthony's Hospital, Dzodze, in the Volta Region of Ghana as well all mothers who participated in this study. Further thanks to all whose works helped in putting this work together.

\section{Funding}

No external funding was received for this study. The researchers themselves covered all cost related to this research.

\section{Availability of data and materials}

A complete document of this study and its results can be found at the School of Medical Sciences Library of the Kwame Nkrumah University of Science and Technology, Kumasi.

\section{Authors' contributions}

The collection of data was done by the fifth author (EA). The first author (RA) did the secondary data compilation, data analysis, and interpretation. The second and third authors (EA and JA) revised the manuscript thoroughly with their expertise. In the analysis of data, all authors played a significant part as well as in designing and preparing the manuscript. Proofreading and the final approval process were also shared accordingly among all authors, and all authors have agreed to its submission for publication.

\section{Ethics approval and consent to participate}

Ethical clearance was obtained from the committee on Human Research Publications and Ethics (CHRPE) of the Kwame Nkrumah University of Science and Technology.

An introductory letter from the Department of Midwifery of the Kwame Nkrumah University of Science and Technology was obtained to embark on the study. Permission was obtained from the administrator of St Anthony's Hospital to carry out the study. All information from the client's folder was treated confidentially. The identity of the study respondents was kept confidential throughout the study. In order to maintain anonymity, participants' identity was not disclosed for this study. The administrators of the hospital approved the use of the facility for the study, and ethical approval was obtained from them

\section{Consent for publication}

Not applicable

\section{Competing interests}

The authors declare that they have no competing interests.

\section{Publisher's Note}

Springer Nature remains neutral with regard to jurisdictional claims in published maps and institutional affiliations.

\section{Author details}

${ }^{1}$ Centre for Disability and Rehabilitation Studies, Department of Community Health, Kwame Nkrumah University of Science and Technology, Kumasi, Ghana. ${ }^{2}$ Kwame Nkrumah University of Science and Technology, Kumasi, Ghana. ${ }^{3}$ School of Public Health, Department of Health Education and Promotion, Kwame Nkrumah University of Science and Technology, Kumasi, Ghana. ${ }^{4}$ Department of Midwifery, Kwame Nkrumah University of Science and Technology, Kumasi, Ghana.

Received: 8 January 2019 Accepted: 6 May 2019

Published online: 16 May 2019

\section{References}

1. AbouZahr C. Global burden of maternal death and disability. Br Med Bull. 2003;67(1):1-1.

2. Haider BA, Bhutta ZA. Birth asphyxia in developing countries: current status and public health implications. Curr Probl Pediatr Adolesc Health Care. 2006;36(5):178-88

3. Halloran DR, McClure E, Chakraborty H, Chomba E, Wright LL, Carlo WA. Birth asphyxia survivors in a developing country. J Perinatol. 2009;29(3):243.

4. Lawn JE, Blencowe H, Pattinson R, Cousens S, Kumar R, Ibiebele I, Gardosi J, Day LT, Stanton C, Lancet's stillbirths series steering committee. Stillbirths: Where? When? Why? How to make the data count?. Lancet 2011;377(9775):1448-1463.

5. Simunek VZ. Définition de l'asphyxie intrapartum et conséquences sur le devenir. La Revue Sage-Femme. 2008;7(2):79-86.

6. de Vries LS, Jongmans MJ. Long-term outcome after neonatal hypoxicischaemic encephalopathy. Arch Dis Child Fetal Neonatal Ed. 2010;95:F220-4

7. Hansen AR, Soul JS. 55 perinatal asphyxia and hypoxic-ischemic encephalopathy. Manual of neonatal care; 2011. p. 711.

8. Brodsky MC. Pediatric neuro-ophthalmology. New York: Springer Science \& Business Media; 2010. p. 23.

9. Gorgos A. Parental projections of developmental outcome, quality of life and coping in children who require neonatal intensive care. 2015.

10. Korkman M, Liikanen A, Fellman V. Neuropsychological consequences of very low birth weight and asphyxia at term: follow-up until school-age. J Clin Exp Neuropsychol. 1996:18(2):220-33.

11. Prosje MA. Asphyxia, Encyclopedia of child behavior and development; 2011. p. 148-51.

12. Gadian DG, Aicardi J, Watkins KE, Porter DA, Mishkin M, Vargha-Khadem F. Developmental amnesia associated with early hypoxic-ischaemic injury. Brain. 2000;123(3):499-507.

13. Robertson CM, Finer NN. Long-term follow-up of term neonates with perinatal asphyxia. Clin Perinatol. 1993;20(2):483-500.

14. Gualtieri CT. Brain injury and mental retardation: psychopharmacology and neuropsychiatry. Philadelphia: Lippincott Williams \& Wilkins; 2002.

15. Campbell OM, Graham WJ, Lancet Maternal Survival Series steering group. Strategies for reducing maternal mortality: getting on with what works. Lancet 2006;368(9543):1284-1299.

16. Mathibe-Neke JM, Lebeko FL, Motupa B. The partograph: a labour management tool or a midwifery record? Int J Nursing Midwifery. 2013; 5(8):145-53.

17. Lavender T, Hart A, Smyth RM. Effect of partogram use on outcomes for women in spontaneous labour at term. Cochrane Database Syst Rev. 2008;4. http://dx.doi.org/10.1002/14651858.cd005461.

18. Mathai M. The partograph for the prevention of obstructed labour. Clin Obstet Gynaecol. 2009;52(2):256-69.

19. Hess DR. Retrospective studies and chart reviews. Respir Care. 2004; 49(10):1171-4.

20. Yamane T. Elementary sampling theory; 1967.

21. Floyd L. Helping midwives in Ghana to reduce maternal mortality. Afr J Midwifery Womens Health. 2013;7(1):34-8.

22. Opoku BK, Nguah SB. Utilisation of the modified WHO partograph in assessing the progress of labour in a metropolitan area in Ghana. Res J Womens Health. 2015;2(1):2.

23. Ogwang S, Karyabakabo Z, Rutebemberwa E. Assessment of partogram use during labour in Rujumbura Health Sub District, Rukungiri district, Uganda. Afr Health Sci. 2009:9(2):27-34.

24. Fesseha N, Getachew A, Hiluf M, Gebrehiwot Y, Bailey P. A national review of cesarean delivery in Ethiopia. Int J Gynecol Obstet. 2011; 115(1):106-11. 
25. Mdeo PF. Quality of partogram recording and perinatal outcomes at Muhimili National Hospital. Tanzania: Muhimbili University of Health and Allied Sciences; 2012. Retrieved from http://dspace.muhas.ac.tz:8080/xmlui/handle/123456789/ 655.

26. Jere JA. Used of partographs in women in labour at Mulanje District Hospital in Malawi (Doctoral dissertation); 2014.

27. Kitila SB, Gmariam A, Molla A, Nemera G. Utilization of partograph during labour and birth outcomes at Jimma University. J Pregnancy Child Health. 2014;1(101):2.

28. Opiah MM, Ofi AB, Essien EJ, Monjok E. Knowledge and utilisation of the partograph among midwives in the Niger Delta Region of Nigeria. African journal of reproductive health; 2012. p. 125-32.

29. Kwast BE, Rogerson $\mathrm{G}$. An analysis of the duration of labour, the mode of delivery and outcome in Queen Elizabeth Hospital, before and after the use of the partograph. Malawi: Internal publication; 1973.

30. Bosse $G$, Massawe $S$, Jahna A. The partograph in daily practice: it's quality that matters. Int J Gynaecol Obstet. 2007;77:243-244.31.

31. Nyamtema A, Urassa D, Massawe S, Lindmark G, vanRoosmalen J. Partographuse in Dar es Salaam perinatal care study. Int J Gynaecol Obstet. 2006;100(1):37-40.32.

32. Fahdhy $\mathrm{M}$, Chongsuvivatwong V. Evaluation of World Health Organization partograph implementation by midwives for maternity home birth in Medan, Indonesia. Midwifery. Elsevier BV; 2005 21(4):301-310. Available from: https://doi.org/10.1016/j.midw.2004.12.010

33. Thorsen VC, Sundby J. Piecing together the maternal death puzzle through narratives: the three delays model revisited. PLoS One. 2012;7(12):e52090.

34. World Health Organization. World Health Organization partograph in management of labour. The Lancet. Elsevier BV; 1994;343(8910). Available from: https://doi.org/10.1016/s0140-6736(94)92528-3

35. Harvey SA, Ayabaca P, Bucagu M, Djibrina S, Edson WN, Gbangbade S, et al. Skilled birth attendant competence: an initial assessment in four countries, and implications for the Safe Motherhood movement. International Journal of Gynecology \& Obstetrics. Wiley; 2004;87(2):203-210. Available from: https://doi.org/10.1016/j.jpg.2004.06.017

36. Javed I, Bhutta S, Shoaib T. Role of partogram in preventing prolonged labour. J Pak Med Assoc. 2007;57(8):408-11.

37. Hofmeyr G. Obstructed labour: using better technologies to reduce mortality. In: International Journal of Gynecology \& Obstetrics, vol. 85: Wiley; 2004. p. S62-72. Available from: https://doi.org/10.1016/i.jgo.2004.01.011.

38. Bogale $D$, Markos D. Knowledge of obstetric danger signs among childbearing age women in Goba district, Ethiopia: a cross-sectional study. BMC Pregnancy Childbirth. 2015;15(1):77.

39. Burkhalter B, Jennings L. Comparison of two methods for determining provider attendance during normal labour and delivery: results from Benin Ecuador Jamaica and Rwanda. 2006

40. Oladapo OT, Daniel OJ, Olatunji AO. Knowledge and use of the partograph among healthcare personnel at the peripheral maternity centres in Nigeria. Journal of Obstetrics and Gynaecology. Informa UK Limited; 2006;26(6):538541. Available from: https://doi.org/10.1080/01443610600811243

41. Mercer SW, Sevar K, Sadutshan TD. Using a clinical audit to improve the quality of obstetric care at the Tibetan Delek Hospital in North India: a longitudinal study. Reproductive Health. Springer Nature; 2006 3(1). Available from: https://doi.org/10.1186/1742-4755-3-4

Ready to submit your research? Choose BMC and benefit from:

- fast, convenient online submission

- thorough peer review by experienced researchers in your field

- rapid publication on acceptance

- support for research data, including large and complex data types

- gold Open Access which fosters wider collaboration and increased citations

- maximum visibility for your research: over $100 \mathrm{M}$ website views per year

At $\mathrm{BMC}$, research is always in progress.

Learn more biomedcentral.com/submissions 